\title{
Oviductal microvesicles and their effect on in vitro maturation of canine oocytes
}

\author{
Anna Lange-Consiglioº , Claudia Perrini ${ }^{2}$, Giulia Albini², Silvia Modina ${ }^{3}$, Valentina Lodde ${ }^{3}$, \\ Eleonora Orsini ${ }^{2}$, Paola Esposti ${ }^{2}$ and Fausto Cremonesi ${ }^{1,2}$ \\ ${ }^{1}$ Reproduction Unit, Centro Clinico-Veterinario e Zootecnico-Sperimentale di Ateneo, Università degli Studi di \\ Milano, Lodi, Italy, ${ }^{2}$ Department of Veterinary Medicine, Università Degli Studi di Milano, Milano, Italy, and \\ ${ }^{3}$ Department of Health, Animal Science and Food Safety, Università Degli Studi di Milano, Milano, Italy \\ Correspondence should be addressed to A Lange-Consiglio; Email: anna.langeconsiglio@unimi.it
}

\begin{abstract}
The effect of conditioned medium (CM) or microvesicles (MVs), secreted by multicellular spheroids of oviductal cells, and the involvement of some microRNAs (miRNAs) were investigated in canine oocyte maturation. To generate CM, spheroids were cultured for 3 days. MVs were obtained by ultracentrifugation of $\mathrm{CM}$ at 100,000 $\mathrm{g}$ and measured for size and concentration by NanoSight instrument. Cumulus-oocyte complexes (COCs) were matured at $38.5^{\circ} \mathrm{C}$ with $5 \% \mathrm{CO}_{2}$ and $5 \%$ of $\mathrm{O}_{2}$ in synthetic oviductal fluid (SOF) in biphasic systems: for $24 \mathrm{~h}$, with $5.0 \mu \mathrm{g} / \mathrm{mL}$ of $\mathrm{LH}$ and for other $48 \mathrm{~h}$ with $10 \%$ oestrous bitch serum. SOF was used as control (CTR) or supplemented with 10\% CM or 25-50-75-100-150 $\times 10^{6} \mathrm{MVs} / \mathrm{mL}$ labeled with PKH-26. Results show that multicellular aggregates secreted shedding vesicles. By fluorescence microscopy, the incorporation of labeled MVs was visible only at $72 \mathrm{~h}$ in oocyte cytoplasm. These MVs had a positive effect $(P<0.05)$ on maturation rate $(\mathrm{MII})$ at the concentration of 75 and $100 \times 10^{6} \mathrm{MVs} /$ $\mathrm{mL}$ compared to CM and CTR $\left(20.34 \%\right.$ and $21.82 \%$ vs $9.09 \%$ and $8.66 \%$ respectively). The concentration of $150 \times 10^{6} \mathrm{MVs} / \mathrm{mL}$ provided only $9.26 \%$ of MII. The expression of three specific miRNAs (miR-30b, miR-375 and miR-503) was studied. The lower rate of MII with the higher concentration of MVs is possibly due to the high level of miR-375. In conclusion, the oviductal MVs could be involved in cellular trafficking during oocyte maturation and their possible use in vitro could facilitate the exploitment of canine reproductive biotechnologies.

Reproduction (2017) 154 167-180
\end{abstract}

\section{Introduction}

The limited efficiency of canine oocytes in vitro maturation (IVM) is conceivably due to either the peculiar reproductive physiology of the dog or to the deficient maturation media employed up to now. Many ultrastructural changes of oocytes, during acquisition of their competence, are common to all mammalian oocytes (Tesoriero 1982), but it is known that canine oocytes display important differences compared to other mammals. Canine oocytes acquire their competence in the intra- and extra-follicular (oviductal) environments (Holst \& Phemister 1971) as they are ovulated spontaneously at an immature diploid stage (germinal vesicle (GV). Subsequent stages of the meiotic maturation, up to completion of meiosis I, and extrusion of the first polar body (stage of metaphase II-MII) occur in the oviduct. Although the exact time of oocyte maturation has not been determined, it appears not to occur until 2 or 3 days after ovulation (Holst \& Phemister 1971). Moreover, canine oocyte shows large amounts of lipid yolk material (Guraya 1965) and the persistence of the cumulus oophorus for several days, until after fertilization (Holst \& Phemister 1971).

In order to reproduce in vitro the intratubal conditions, Hewitt and England (1998) were the first researchers who investigated the effect of introducing oviductal elements, such as synthetic oviductal fluid (SOF) to the culture environment or co-culturing with isolated canine oviductal epithelial cells. Afterward, canine IVM has been assessed in co-culture with other cell types (Otoi et al. 2000a, Hatoya et al. 2006, Saikhun et al. 2008) or even after insertion of the oocytes into an explanted oviduct cultured in vitro (Luvoni et al. 2003). Moreover, to mimic the in vivo environment, Songsasen et al. (2002) and Silva et al. (2009) suggested to culture canine oocytes in low oxygen tension and Nickson et al. (1993) in the presence of $10 \%$ of oestrus bitch serum.

Whatever the maturation system, only $10-20 \%$ of oocytes reaches metaphase I (MI) or metaphase II (MII) stages (Luvoni et al. 2005). The few MII oocytes are unable to be fertilized and undergo early embryonic development (Viaris de Lesegno et al. 2008, 
Chebrout et al. 2009). Low rates of MIl could also be due to low competence of the selected oocytes or inadequate culture conditions (Luvoni et al. 2005). Concerning oocytes selection, the age of the donor bitch (Hewitt \& England 1998, Songsasen et al. 2002), the stage of the reproductive cycle (Yamada et al. 1993, Otoi et al. 2001), the oocyte diameter (Hewitt \& England 1998, Otoi et al. $2000 b$ ) and the size of the ovarian follicle (Songsasen \& Wildt 2005), are factors influencing meiotic competence of canine oocytes cultured in vitro. In particular, oocyte diameter may be a useful selection parameter. It has been reported that large oocytes $(>120 \mu \mathrm{m}$ diameter) show a higher frequency of maturation than oocytes $<110 \mu \mathrm{m}$ diameter (Otoi et al. 2000a, Ariu et al. 2012).

Regarding the IVM media, other attempts have been made to identify the factors involved in the resumption and progression of maturation in vivo, so that improvements in cultural conditions have been achieved. Indeed, recently, a biphasic system based on a sequential combination of different hormones indicated that $\mathrm{MI}+\mathrm{MII}$ rates were higher among oocytes cultured in sequential media than those matured in the traditional way (Evecen et al. 2011). This system improved cortical granule distribution (an indication of cytoplasmic maturation) and its relationship to the nuclear status (Apparicio et al. 2014), although the MII rate remained around $20 \%$. This clearly indicates the need to further study the mechanisms leading to canine oocyte maturation and to identify specific signals that induce in vivo meiotic resumption and progression. The co-culture system provided the best results compared to the use of standard TCM-199 medium, but achievements are still far from the maturation rate obtained in the oviductal environment in vivo that, in the dog, is beneficial for supporting oocytes maturation. In vivo, canine oocytes are exposed to the oviductal secretions and they are in contact with oviductal mucosa for long time, and this may be crucial in the acquisition of oocyte competence. The advantages of the in vitro co-culture system suggest that paracrine mechanisms of communication exist between oviductal cells and oocytes. In fact, various growth factors, receptors and binding proteins are secreted by cells in the culture medium, but they could also be produced by the oocytes themselves (Gilchrist et al. 2008). Conditioned media (CM), composed of factors secreted by cells during their culture, were mainly developed and used in in vitro bovine embryo production. Some of these cell-free media, produced, for example, by culturing granulosa, cumulus or oviductal cells, demonstrated a similar effect in the development of embryos produced by co-culture systems (Rieger et al. 1995) or had a positive effect on the quality of in vitro-produced bovine embryos (Lopera-Vasquez et al. 2016). Conditioned medium is composed of soluble factor, but recent studies have also uncovered the existence of microvesicles (MVs), which are released by cells into the extracellular environment
(Ratajczak et al. 2006, Camussi et al. 2010). These MVs have been shown to contain proteins, lipids (specifically high levels of sphingomyelins), a variety of RNA species, including microRNAs (miRNAs) and mRNA fragments (Thery et al. 2009). Microvesicles could serve as vehicles for the transfer of these molecules between cells (Zhang et al. 2009, Raposo \& Stoorvogel 2013). The in vitro use of feeder cell or CM probably involves MVs that may participate in this required cross-talk, as studied in the bovine in vitro embryo production by Lopera-Vasquez et al. (2016).

To understand the signals that are carried from epithelial oviductal cells to canine oocytes, we studied the effect of different components of the secretome of this cell line. This effect has never been studied and, since it is difficult to study these communications in vivo, we tested these interactions in in vitro canine oocyte maturation. Canine oviductal cell secretome, composed of $\mathrm{CM}$ in toto, MVs and supernatant (SN), collected after removal of MVs, was investigated to know which of these components, if not all, have effects on oocyte maturation, in terms of MII rate. In vitro culture was performed taking into account all the best conditions previously described, as the use of oocytes with diameter of $110-120 \mu \mathrm{m}$ or greater, the biphasic system, the SOF medium and the low oxygen tension.

\section{Materials and methods}

All chemicals in this study were purchased from Sigma-Aldrich unless otherwise stated, whereas disposable materials were purchased from Euroclone (Milano, Italy).

\section{Experimental design}

This study explores the MII production rate of canine oocytes co-cultured with oviductal epithelial cell in monolayer or in multicellular spheroids. Moreover, this study investigates the effects of supplementing the IVM medium with $10 \%$ of CM in toto or SN or with different amounts of MVs. The ability of oocytes to uptake labeled MVs and the identification of some miRNAs, responsible for oocytes maturation in other species, both in oviductal cells and in the MVs, are also investigated.

\section{Animals}

To isolate epithelial cell and oocytes, oviducts and ovaries were recovered from 64 healthy adult domestic bitches (over 12 months old) referred to the University Veterinary Hospital for ovariectomy at owners convenience. In this study, after approval by the Ethical Committee of the University of Milan and written owner's consent, all procedures were carried following standard veterinary practice and in accordance to 2010/63 EU directive on animal protection and Italian Law (D.L. No. 116/1992).

To collect epithelial cells, oviducts were obtained from bitches at oestrous stage, while to collect oocytes, ovaries of bitches at all different stages of oestrous cycle were used. 
The stage of oestrous cycle of these animals was determined through the evaluation of ovarian morphology. Three stages were differentiated:

- Anaestrus, when ovaries did not show apparent follicles or corpora lutea.

- Estrus (follicular stage), when on the ovarian surface there were one or more 2-8 $\mathrm{mm}$ in diameter follicles.

- Diestrus, when one or more corpora lutea were present on the ovarian surface.

In addition, the oestrous stage was confirmed by vaginal cytology and blood serum progesterone concentration.

\section{Cell isolation and culture}

To obtain oviductal epithelial cells, ovaries with ovarian bursa were maintained in physiological saline solution $(0.9 \% \mathrm{NaCl})$, supplemented with $1 \%$ penicillin $(100 \mathrm{IU} / \mathrm{mL})-$ streptomycin $(100 \mathrm{mg} / \mathrm{mL})$ at $38^{\circ} \mathrm{C}$ and transported to the laboratory within $1 \mathrm{~h}$. Oviducts were dissected free from ovarian bursa fat and washed in fresh physiological saline solution. The oviductal lumen was rinsed with phosphate-buffered saline (PBS), supplemented with $10 \%$ fetal calf serum (FCS), by means of a fine blunt needle to remove possible oocytes within the lumen. Then, two methods were assessed to isolate epithelial cells for co-culture in canine oocyte IVM. In the first method, oviducts were slit lengthways and the luminal surface was lightly scraped with a microblade. In the second method, oviducts were squeezed out by sterile tweezer to release epithelial cells into the culture medium composed of high-glucose Dulbecco modified Eagle's medium (HG-DMEM) supplemented with $10 \%$ of FCS, $2 \mathrm{mM}$ L-glutamine and penicillin $(100 \mathrm{IU} / \mathrm{mL})-$ streptomycin $(100 \mathrm{mg} / \mathrm{mL})$. This method has been reported for the sampling of oviductal epithelial cells in the cow (Eyestone \& First 1989, Xu et al. 1992). By the first method, only isolated cells were collected. These cells were stained with trypan blue to assess their viability, and concentration was measured using a Burker chamber. Approximately, $60 \times 10^{4}$ cells $/ \mathrm{mL} /$ well were seeded and cultured in monolayer (Fig. 1A).

By the second method, in addition to isolated cells, oviductal exfoliated mucosal portions were observed at microscopy. They were collected through a $10 \mu \mathrm{L}$ micropipette tip and seeded in different wells of a 4-well dish. The culture of these structures was performed in suspension (Fig. 1B) for three days until they organized themselves into multicellular spheroids. The presence of cilia maintained them in constant rotary motion (Fig. $1 \mathrm{C}$ ).

For both kinds of epithelial cells, the culture was performed at $38.5^{\circ} \mathrm{C}$ in an atmosphere with $5 \%$ of $\mathrm{CO}_{2}$ and $90 \%$ of humidity with culture medium. At the time of their formation, multicellular spheroids were collected and used, in addition to canine IVM, for electron microscopy analysis, immunocytochemistry and CM production.

\section{Transmission electron microscopy}

For histological and ultrastructural analyses, multicellular spheroids were fixed in a mixture of $2 \%$ paraformaldehyde and $2.5 \%$ glutaraldehyde in $0.1 \mathrm{M}$ sodium cacodylate buffered solution at $\mathrm{pH} 7.4$ for $1 \mathrm{~h}$ at room temperature. After washing
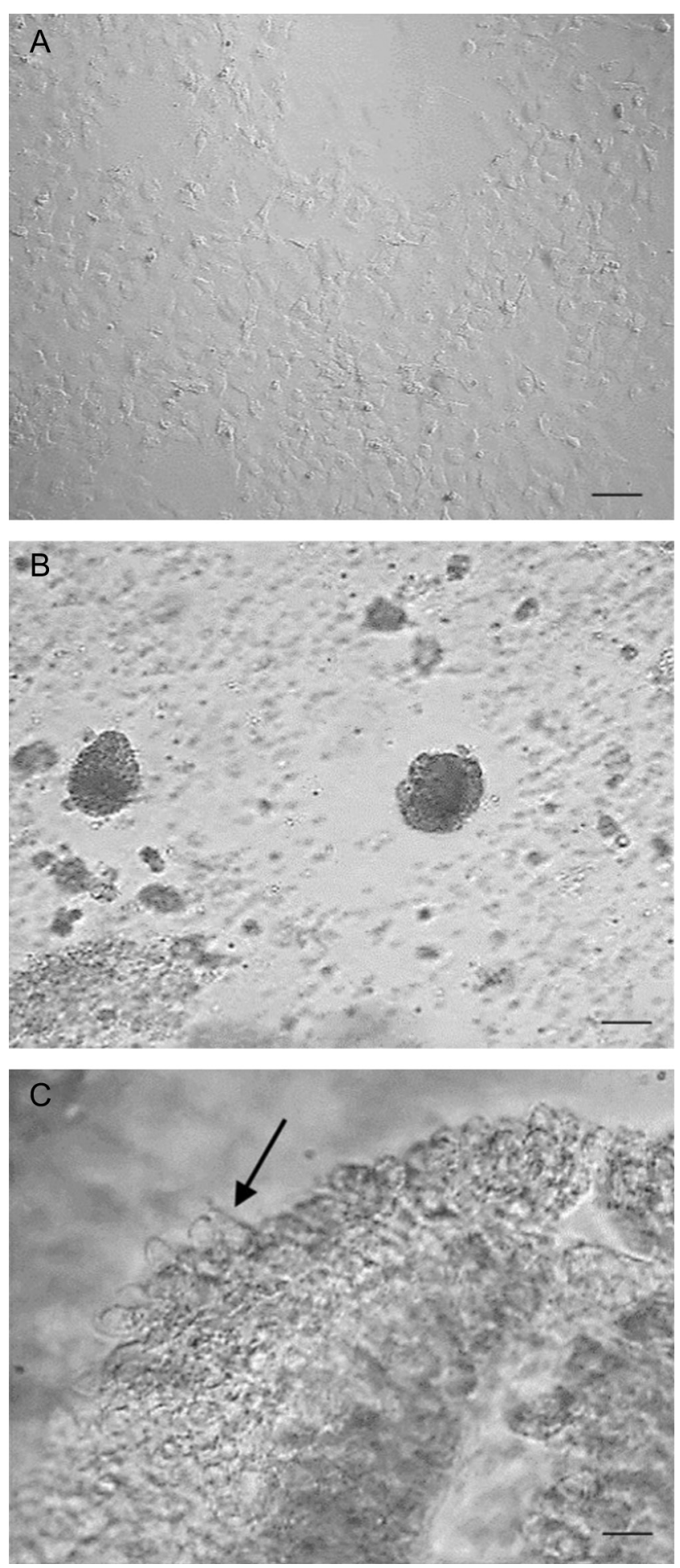

Figure 1 Morphology of oviductal cells. (A) Monolayer of epithelial cells. (B) Multicellular spheroids cultured in suspension. (C) Arrow indicates cilia. Light microscope images. Magnification 20x. Scale bar of figure $(A)=20 \mu \mathrm{m}$; scale bar of figure $(B)=30 \mu \mathrm{m}$; scale bar of figure $(C)=2 \mu \mathrm{m}$.

in the same buffer, samples were post-fixed in $1 \% \mathrm{OsO}_{4}$, $1.5 \%$ potassium ferrocyanide in $0.1 \mathrm{M}$ cacodylate for $1 \mathrm{~h}$ in dark condition on ice. After several washings in distilled 
water, samples were stained with $0.5 \%$ uranyl acetate in water overnight at $4{ }^{\circ} \mathrm{C}$ and, finally, were dehydrated in a graded ethanol series $(30,50,70,80,90,96 \%$ for 5 min each and washed three times with absolute ethanol for $10 \mathrm{~min}$ each). The samples were infiltrated with ethanol and resin (Araldite-Epon) at volumetric proportions of $1: 1$ for $2 \mathrm{~h}$, and then in $100 \%$ Epon twice for $1 \mathrm{~h}$ each and, finally, polymerized at $60^{\circ} \mathrm{C}$ for $48 \mathrm{~h}$. Sectioning was performed using an Ultracut $\mathrm{E}$ microtome (Reichert, Austria). Semithin sections of about $0.5 \mu \mathrm{m}$ were collected onto microscope slides and stained with methylene blue-azure II and basic fuchsine (D'Amico et al. 2005). For the ultrastructural analysis, sections of $70 \mathrm{~nm}$ were collected on 300-mesh uncoated copper grid. All thin sections were not counterstained and observed with a Zeiss LEO 912ab Energy Filtering TEM operating at $120 \mathrm{kV}$. Digital images were acquired using a CCD-BM/1 K system operating with the iTEM (Olympus Soft Imaging Solutions).

\section{Immunocytochemistry of multicellular spheroids}

Indirect immunofluorescence was performed to assess the expression of cytokeratin, a protein normally found in cells of epithelial origin and vimentin, a cytoskeletal protein expressed in cells of mesenchymal origin. Multicellular spheroids were washed in PBS supplemented with bovine serum albumin (BSA $0.03 \mathrm{mg} / \mathrm{mL})$, fixed in $4 \%$ paraformaldeyde $\left(20-30 \mathrm{~min}\right.$ at $\left.4^{\circ} \mathrm{C}\right)$ and washed in PBS for $10 \mathrm{~min}$. Samples were permeabilized with $0.3 \%$ Triton X100, in PBS for $30 \mathrm{~min}$ at room temperature (RT) and washed in PBS supplemented with 1\% BSA (PBS/1\% BSA). Non-specific binding was blocked by incubating the samples in 20\% normal donkey serum, 1\% BSA and $0.1 \%$ Triton $\mathrm{X} 100$ in PBS for $30 \mathrm{~min}$ at RT. The samples were incubated $1: 1000$, overnight at $4^{\circ} \mathrm{C}$ with a mouse monoclonal anti-Pan-cytokeratin, (AE1/AE3 Zymed San Francisco, CA, USA) or a mouse monoclonal anti vimentin (VIM, clone 3B4 Agilent Technologies Dako, Denmark, 1:1000) in PBS/1\% BSA. Samples were extensively washed in PBS/1\% BSA and incubated for $1 \mathrm{~h}$ at RT with a donkey anti-mouse secondary antibody conjugated with Alexa Fluor 488 (Invitrogen), diluted 1:500 in PBS containing 1\% BSA. Samples were rinsed twice in $\mathrm{PBS} / 1 \% \mathrm{BSA}$ and mounted in an antifade medium (Vecta Shield; Vector Laboratories, Inc., Burlingame, CA, USA) supplemented with DAPI dilactate $(1 \mu \mathrm{g} / \mathrm{mL})$. Samples were analyzed on an epifluorescence microscope (Eclipse E600; Nikon) equipped with a $40 \times$ objective, a digital camera and software (NIS, Elements Imaging Software; Nikon). Negative controls were performed by omitting the primary antibody. The excitation wavelength for DAPI was $330-350 \mathrm{~nm}$ and for Alexa Fluor488 (FITC) was 465-495 nm.

\section{Conditioned medium, microvescicles and supernatant production}

Conditioned medium, MVs and SN were obtained by multicellular spheroids only. Multicellular spheroids were cultured for 3 days with $1 \mathrm{~mL}$ per well of a serum-free culture medium (Lonza, Milano, Italy) added with $1 \%$ penicillin $(100 \mathrm{IU} / \mathrm{mL})$-streptomycin $(100 \mathrm{mg} / \mathrm{mL})$ and $2 \mathrm{mM} \mathrm{L-glutamine.}$ Conditioned media of three different samples were collected, pooled and centrifuged at $2500 \mathrm{~g}$ for $20 \mathrm{~min}$ to remove the cellular debris. A portion of this CM in toto was stored at $-20^{\circ} \mathrm{C}$. To obtain $\mathrm{MVs}$ and $\mathrm{SN}$, another aliquot of $\mathrm{CM}$ was ultracentrifuged (Beckman Coulter Optima L - 100K) at $100,000 \mathrm{~g}$ for $1 \mathrm{~h}$ at $4^{\circ} \mathrm{C}$ and $\mathrm{SN}$ was collected and stored at $-20^{\circ} \mathrm{C}$ for later use. The pellet was washed in serum-free medium 199 containing N-2-hydroxyethylpiperazine-N-2ethanesulfonic acid (HEPES) $25 \mathrm{mM}$ and submitted to a second ultracentrifugation under the same conditions. The resulting pellet, composed of $\mathrm{MVs}$, was fractionated for $\mathrm{MVs}$ analysis or used for the in vitro test.

\section{Measurements of $M V s$}

Size and concentration of MVs secreted by multicellular spheroids were evaluated by NanoSight LM10 instrument (Nanoparticle tracking analysis, NTA, NanoSight Ltd., Amesbury, UK), which permits discrimination of microparticles less than $1 \mu \mathrm{m}$ in diameter. The software (NTA 2.0 analytic software) allows the analysis of video images of particle movement under Brownian motion and the calculation of diffusion coefficient, sphere equivalent and hydrodynamic radius of particles by using the Strokes-Einstein equation. This instrument is equipped with a $405 \mathrm{~nm}$ laser and a high-sensitivity sCMOS camera (OrcaFlash2.8, Hamamatsu C11440, NanoSight Ltd). Videos were collected and analyzed using the NTA software with the minimal expected particle size, minimum track length and blur setting, all set to automatic. Ambient temperature was recorded manually and did not exceed $25^{\circ} \mathrm{C}$. Five microliters of each sample were diluted in sterile physiological solution to a final volume of $1 \mathrm{~mL}$. Samples were analyzed within $15 \mathrm{~min}$ of the initial dilution with a delay of $10 \mathrm{~s}$ between sample introduction and the start of the measurement. For each sample, multiple videos of 30-s duration were recorded generating replicate histograms that were averaged.

\section{MVs labeling with PKH-26}

To trace MVs in vitro by fluorescence microscopy, MVs from spheroidal aggregates were labeled with the red fluorescence aliphatic chromophore intercalating into lipid bilayers, $\mathrm{PKH}-26$ dye. Briefly, after ultracentrifugation, the MV pellet was diluted to $1 \mathrm{~mL}$ with $\mathrm{PKH}-26$ kit solution and $2 \mu \mathrm{L}$ of fluorochrome were added to this suspension and incubated for $15 \mathrm{~min}$ at $38.5^{\circ} \mathrm{C}$. Thereafter, $7 \mathrm{~mL}$ of serum-free HG-DMEM were added to the suspension that was ultracentrifuged again at 100,000 $\mathbf{g}$ for $1 \mathrm{~h}$ at $4^{\circ} \mathrm{C}$. The final pellet was immediately resuspended in HG-DMEM and stored at $-20^{\circ} \mathrm{C}$.

\section{miRNA analyses by RNA extraction and PCR amplification}

Microvesicle pellet was subjected to RNase digestion to remove extraneous ribonucleic acids (Skog et al. 2008). Total RNA was isolated from pool of different MVs and multicellular spheroid preparations using the NucleoSpin mRNA kit (Macherey-Nagel, Germany), in combination with TRIzol lysis and purification of small and large RNA in one fraction (total 
RNA). RNAs were quantified using a NanoDrop ND-1000 spectrophotometer (NanoDrop Technologies, Wilmington, DE, USA). RNA quality was checked using the Agilent Bioanalyser 2100 (Agilent), where the presence of small RNAs was verified in both MV and cell samples.

RNAs from all samples were reverse transcribed with the miScript Reverse Transcription Kit. The cDNA was then pre-amplified by using miScript PreAMP PCR Kit (all from Qiagen), following manufacturer instruction with some modification: miScript PreAMP Primer Mix was replaced with miR-specific primers: hsa-miR-30b, has-miR-375 and cfa-miR-503, SNORD95 as forward primer, and miScript Universal Primer as reverse primer in separate reactions. Homo sapiens hsa miRNAs were perfectly homologous with Canis lupus familiaris cfa miRNA sequence for miR-30b and miR-375. PCR was performed on pre-amplified products by using PCR Master Mix (2x) (Thermo Fisher Scientific), with same primer couple: hsa-miR-30b, hsa-miR-375, cfa-miR-503 and SNORD95 in combination with miScript Universal Primer. The small nucleolar snoRNA, C/D Box 95 SNORD95 was used as positive control. Negative controls using water in place of the pre-Amp product were performed alongside each reaction. The cycling conditions were $3 \mathrm{~min}$ at $95^{\circ} \mathrm{C}$, followed by 35 cycles of $30 \mathrm{~s}$ at $95^{\circ} \mathrm{C}, 30 \mathrm{~s}$ at $58^{\circ} \mathrm{C}$ and $1 \mathrm{~min}$ at $72^{\circ} \mathrm{C}$, and finally 7 min at $72^{\circ} \mathrm{C}$. The amplified PCR products were separated electrophoretically on $2.5 \%$ agarose gels, and visualized under UV, by using GeneRuler 50 bp as DNA ladder (Thermo Fisher Scientific).

\section{Bitch serum production}

To reproduce the in vivo conditions as closely as possible, we used serum obtained by three bitches at peri-ovulation oestrous stage, as determined by progesterone concentration and vaginal cytology. The serum was prepared from blood that after clotting was centrifuged at $3000 \mathrm{~g}$ for $10 \mathrm{~min}$. The supernatant was collected and serum was heat-inactivated for $30 \mathrm{~min}$ at $56^{\circ} \mathrm{C}$ and stored at $-20^{\circ} \mathrm{C}$ until use. Serum progesterone concentration was evaluated by ELFA method validated for use in the dog by Enzyme Linked Fluorescent Assay (MiniVidas, Biomerieux) (Brugger et al. 2011).

\section{Collection of ovaries and compact COCs retrieval}

Ovaries were collected from bitches during routine ovariectomy at University Veterinary clinics. No attempt was made to divide the oocytes according to the stage of the oestrous cycle of the animals. After excision, ovaries were put in a sterile container in physiological solution supplemented with $1 \%$ penicillin-streptomycin. Within $1 \mathrm{~h}$ of collection, ovaries were washed several times in fresh PBS and ovarian bursa was removed. Ovaries were put in TCM-199 medium with $25 \mathrm{mM}$ HEPES supplemented with $0.1 \%$ BSA and $1 \%$ penicillin-streptomycin at $38.5^{\circ} \mathrm{C}$ and were sliced repeatedly by scalpel to release oocytes.

After collection, immature oocytes were screened under stereomicroscope and selected based on their diameter and morphology. Damaged oocytes were eliminated (Fig. 2A). The selected oocytes were 110-120 $\mu$ m or more in diameter, darkly pigmented and completely surrounded by two or more layers of cumulus cells (Fig. 2B).

\section{In vitro maturation of oocytes}

Compact COCs were cultured in 4-wells dishes containing $500 \mu \mathrm{L}$ of culture medium under $500 \mu \mathrm{L}$ of equilibrated paraffin oil for a maximum of 30 oocytes per well. The incubation took place in incubator with $5 \% \mathrm{CO}_{2}, 5 \% \mathrm{O}_{2}$ and $90 \% \mathrm{~N}_{2}$ for $72 \mathrm{~h}$.

The culture medium used was SOF manufactured in laboratory and composed of $\mathrm{NaCl}(1.1 \mathrm{M}), \mathrm{KCl}(72 \mathrm{mM})$, $\mathrm{KH}_{2} \mathrm{PO}_{4}(12 \mathrm{mM}), \mathrm{MgSO}_{4}(7.4 \mathrm{mM})$, DL-lactic acid $(60 \%)$ $(50 \mathrm{mM}), \mathrm{NaHCO}_{3}(250 \mathrm{mM})$, phenol red $(260 \mathrm{mM})$, sodium pyruvate $(100 \mathrm{mM}), \mathrm{CaCl}_{2}$ di-hydrate $(178 \mathrm{mM})$, sodium HEPES $(125 \mathrm{mM})$, acid HEPES $(125 \mathrm{mM})$, L-glutamine $(30.8 \mathrm{mM})$, glycine $(500 \mathrm{mM})$, alanine $(84.2 \mathrm{mM})$, non-essential MEM (100x), BME (100x), myo-inositol $(2.8 \mathrm{mM})$, sodium tri-citrate di-hydrate $(340 \mathrm{mM})$, FBS $(2 \%)$, BSA $(0.005 \mathrm{~g} / \mathrm{mL})$, pyruvate $(11 \mathrm{mg} / \mathrm{mL})$ and gentamicin $(5 \mu \mathrm{L} / \mathrm{mL})$.

The medium was filtered and allowed to equilibrate for $1 \mathrm{~h}$ in the same incubator before being used. SOF was used in
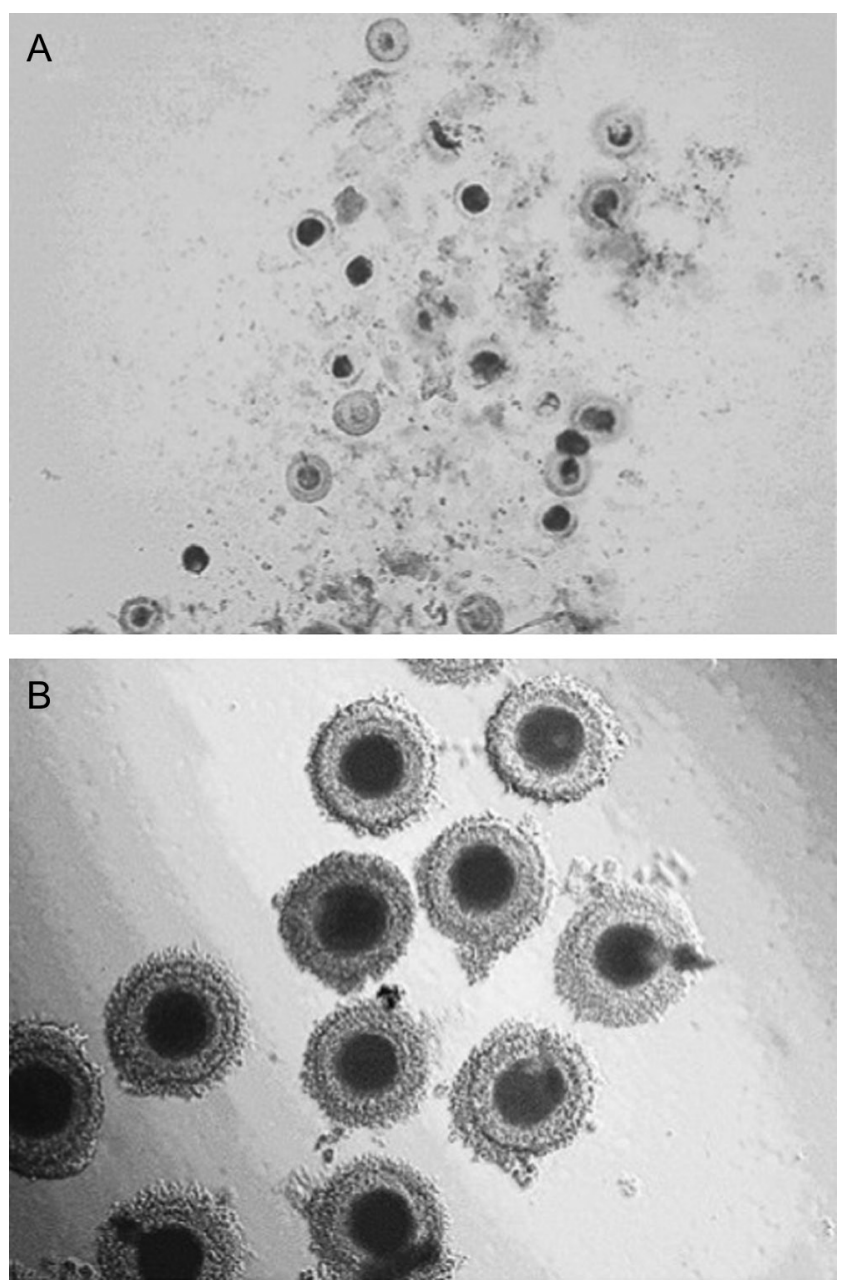

Figure 2 Morphology of oocytes. (A) Canine oocytes discarded after collection. (B) Canine oocytes selected for IVM. 
a biphasic system: for $24 \mathrm{~h}$, COCs were cultured with $5.0 \mu \mathrm{g} /$ $\mathrm{mL}$ of $\mathrm{LH}$ (Lutropin, Vetoquinol) and for other $48 \mathrm{~h}$ with $10 \%$ oestrous bitch serum with progesterone level higher than $10 \mathrm{ng} / \mathrm{mL}$.

In this second step, we tested four experimental conditions: Group 1) co-culture with epithelial cells in monolayer

Group 2) co-culture with multicellular spheroids

Group 3) culture with $10 \%$ of CM secreted by multicellular spheroids

Group 4) culture with $10 \%$ of SN secreted by multicellular spheroids

Group 5) culture with different amounts (25-50-75-100$150 \times 10^{6} / \mathrm{mL}$ ) of MVs secreted by multicellular spheroids. This amount was calculated based on microliters of pellet obtained after centrifugation and on the total amount of MVs found after analysis by NanoSight.

As control group, SOF in biphasic system without CM, SN or MVs was used.

\section{Assessment of meiotic maturation by Hoechst 33342}

At the end of the culture period, irrespective of their morphology, oocytes were removed from the culture drop and washed in PBS for three times. Then, oocytes were denuded by incubation for $10 \mathrm{~min}$ at $38.5^{\circ} \mathrm{C}$ in TCM 199 with $20 \%$ FCS containing $80 \mathrm{IU} / \mathrm{mL}$ hyaluronidase and by aspiration in and out of finely drawn glass pipettes. All oocytes were stained for 15 min at RT in a small drop of PBS supplemented with $10 \mu \mathrm{g} /$ $\mathrm{mL}$ bis-benzimide (Hoechst 33342) on a glass slide. Particular attention was paid to avoid sample exposure to light during staining in order to reduce photo bleaching. The nuclear configuration and chromatin morphology were evaluated under fluorescence microscopy (Olympus BX51) with UV light (353-365 nm excitation and $460 \mathrm{~nm}$ emission) to determine the stage of meiotic maturation. Chromatin configurations were classified as previously described (Kim et al. 2004). GV stage is the so-called meiotic block. Stages indicative of meiosis resumption were germinal vesicle break down (GVBD) (organization and condensation of chromatin into chromosomes), metaphase I (alignment of chromosomes on meiotic spindle) and metaphase II, which was indicated by the presence of the 2 nd metaphase plate (MII) and the first polar body (PB) was extruded. Oocytes with irregular chromatin distribution or absence of chromatin were considered as indicative of degenerated or non-identifiable chromatin material (DEG).

\section{Evaluation of $M V$ uptake by oocytes}

To confirm MVs incorporation into oocyte, a group of oocyte was cultured in SOF supplemented with MVs previously labeled with $\mathrm{PKH}-26$, at a concentration of $100 \times 10^{6} \mathrm{MVs} / \mathrm{mL}$ for $48 \mathrm{~h}$ of IVM. Oocytes were stained with Hoechst 33343 $(10 \mu \mathrm{g} / \mathrm{mL})$ and $\mathrm{MVs}$ incorporation was evaluated under fluorescence by an Olympus BX51 microscope. Labeled MVs were excited at $550 \mathrm{~nm}$ while emission wavelength was set at $567 \mathrm{~nm}$. Hoechst 33342 dye was excited at 353-365 nm while the emission wavelength was set at $460 \mathrm{~nm}$.

\section{Statistical analysis}

Percentages of oocytes reaching various stages of nuclear maturation under the different experimental conditions were statistically analyzed by chi-squared test in a large contingency table and by the Yates correction for continuity. In addition, Fisher's exact test was performed when appropriate (observations $<5$ ). A probability level of $P<0.05$ was considered as significantly different. Data were analyzed with GraphPad Instat 3.00 for Windows (GraphPad Software).

\section{Results}

\section{TEM}

The semithin section indicated that multicellular spheroids are formed by clusters of cells tightly in contact. Several apical protrusions, as well as elongated cilia, were located on the outer cell side of the cluster. Non-ciliated cells showed a more intense staining than ciliated cells (Fig. 3).

TEM observation showed the presence of epithelial cells, ciliated and not ciliated. Ciliated cells were characterized by some endocytic vesicle in the apical region (Fig. 4A and B). Non-ciliated cells often displayed microvilli on the apical protrusion and were characterized by an electron-dense cytoplasm containing a lobate nucleus rich in dispersed heterochromatin, dark granules of secretion in their supranuclear cytoplasm and elongated mitochondria (Fig. 4B and C). The presence of cell junctions in the apical portion of these cells indicates the polarization of these cells (Fig. 4B) that are also closely connected to each other through membrane interdigitations (Fig. 4A, $B$ and $C$ ). Cells with a large nucleus with disperse heterochromatin and voluminous vesicles containing electron-lucent secrete were detected under the epithelial cells (Fig. 4B and D).

\section{Immunocytochemistry}

Multicellular spheroids exhibited positive immunostaining for cytokeratin, normally found in cells of epithelial origin. Cells also exhibited immunostaining for vimentin, a cytoskeletal protein expressed in cells of mesenchymal origin (Fig. 5). This result is indicative of a mixed cell population of both epithelial and mesenchymal cells in these tridimensional structures.

\section{Isolation and measurements of MVs}

NanoSight analysis determined the presence of MVs with size ranging from $50 \mathrm{~nm}$ to $670 \mathrm{~nm}$ for the three samples, with an average of $234 \pm 23 \mathrm{~nm}$. MVs production corresponds to $540 \times 10^{6}$ particles $/ \mathrm{mL}$ of medium. 


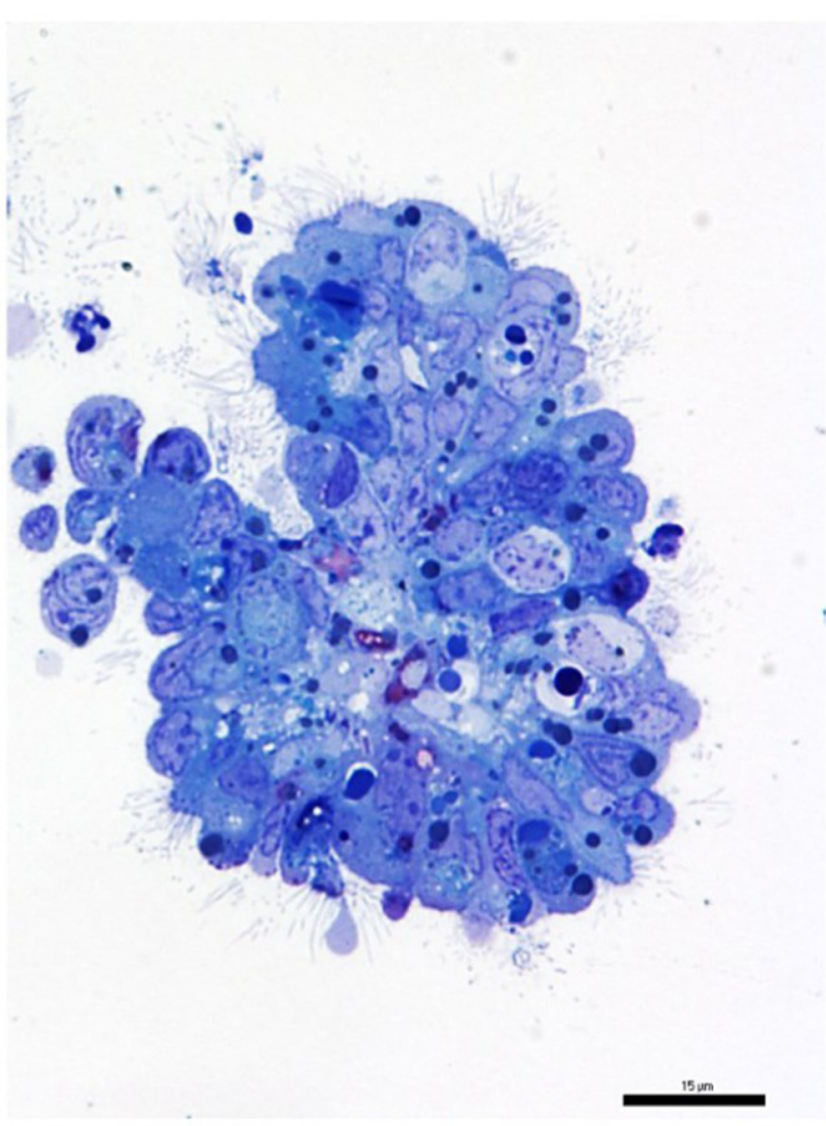

Figure 3 Semithin section. Multicellular spheroid at magnification $63 \times$. Scale bar $15 \mu \mathrm{m}$. A cluster of cells tightly in contact formed this aggregate. Several apical protrusions, as well as elongated cilia, were located on the outer cell side of the cluster.

According to size, these MVs can be defined as shedding vesicles, i.e. vesicles budded directly from the plasma membrane of oviductal cells.

Figure 6 shows an example of NanoSight analysis on MVs released by oviductal multicellular spheroids.

\section{miRNA analyses by RNA extraction and PCR amplification}

Expression of specific miRNA was determined by PCR assay that showed the presence of miR-30b, miR-375 and miR-503 in both MVs and multicellular spheroids (Fig. 7).

\section{Progesterone level of bitch serum}

According to hormonal evaluation by MiniVidas system, progesterone levels of the three bitches on periovulation oestrus stage were 8,12 and $15 \mathrm{ng} / \mathrm{mL}$, with an average of $11.67 \mathrm{ng} / \mathrm{mL}$. The serum samples were used pooled.

\section{Oocytes retrieval and culture}

From 64 ovariectomized bitches, 17 were in anoestrus, 12 in oestrus and 35 in diestrus. A total of 1375 oocytes were obtained from all animals, with an average of 10.74 oocytes per ovary. Oocytes were selected according to their diameter and morphology and, based on these criteria, almost $50 \%$ of oocytes were eliminated and the selected oocytes were spread randomly among different culture media, not taking into account the oestrous cycle stage of the bitches.

In all experimental conditions, at the end of the IVM period, some oocytes showed expansion of cumulus oophorus (Fig. 8).

Based on nuclear morphology showed by Hoechst staining, oocytes were classified as GV (Fig. 9A), germinal vesicle breakdown (GVBD; Fig. 9B), metaphase I (MI; Fig. 9C) and metaphase II (MII; Fig. 9D). Furthermore, degenerated oocytes (DEG) also were counted (Fig. 9E).

The results of the experiments are given in Table 1, with the rates of different nuclear stages.

The maturation rate in the control medium was $8.66 \%$ and all data obtained in other conditions were compared to this result.

The co-culture system with epithelial cells in monolayer provided $10.71 \%$ of MII that is not statistically different $(P<0.05)$ compared to CTR, while co-culture with multicellular spheroids gave $20 \%$ of MII that was significantly higher $(P<0.05)$ than MII rate of CTR, monolayer of epithelial cells, CM (9.09\%) and SN $(7.14 \%)$.

The best conditions for obtaining MII oocytes were the co-culture with $\mathrm{MVs}$ at concentrations varying between 75 and $100 \times 10^{6} / \mathrm{mL}$. Maturation rates were respectively $20.34 \%$ and $21.82 \%$, and they were statistically greater $(P<0.05)$ than control, monolayer of epithelial cells, CM and $\mathrm{SN}$ but similar to the rate of co-culture with multicellular spheroids. Higher concentrations of MVs $\left(150 \times 10^{6}\right)$ showed statistically $(P<0.05)$ lower maturation rates $(9.26 \%)$ compared to the others MV concentrations.

The rate of oocytes that remained at the GV stage was the same in all the experimental conditions. The rate of oocytes with GVBD was statistically higher $(P<0.05)$ in CTR, in oocytes matured on monolayer and in the presence of $\mathrm{CM}$ and $\mathrm{SN}(45.24,47.56$, 38.64 and $44.05 \%$ respectively), but their MII rate was statistically lower $(P<0.05)$ than co-culture system with multicellular spheroids and with MV concentration that provided the best maturation rates.

\section{Evaluation of $M V$ uptake by oocytes}

Microvesicles were abundantly incorporated by cumulus cells, but not in the oocyte cytoplasm, after $48 \mathrm{~h}$ of culture (Fig. 10A). The incorporation of MVs 

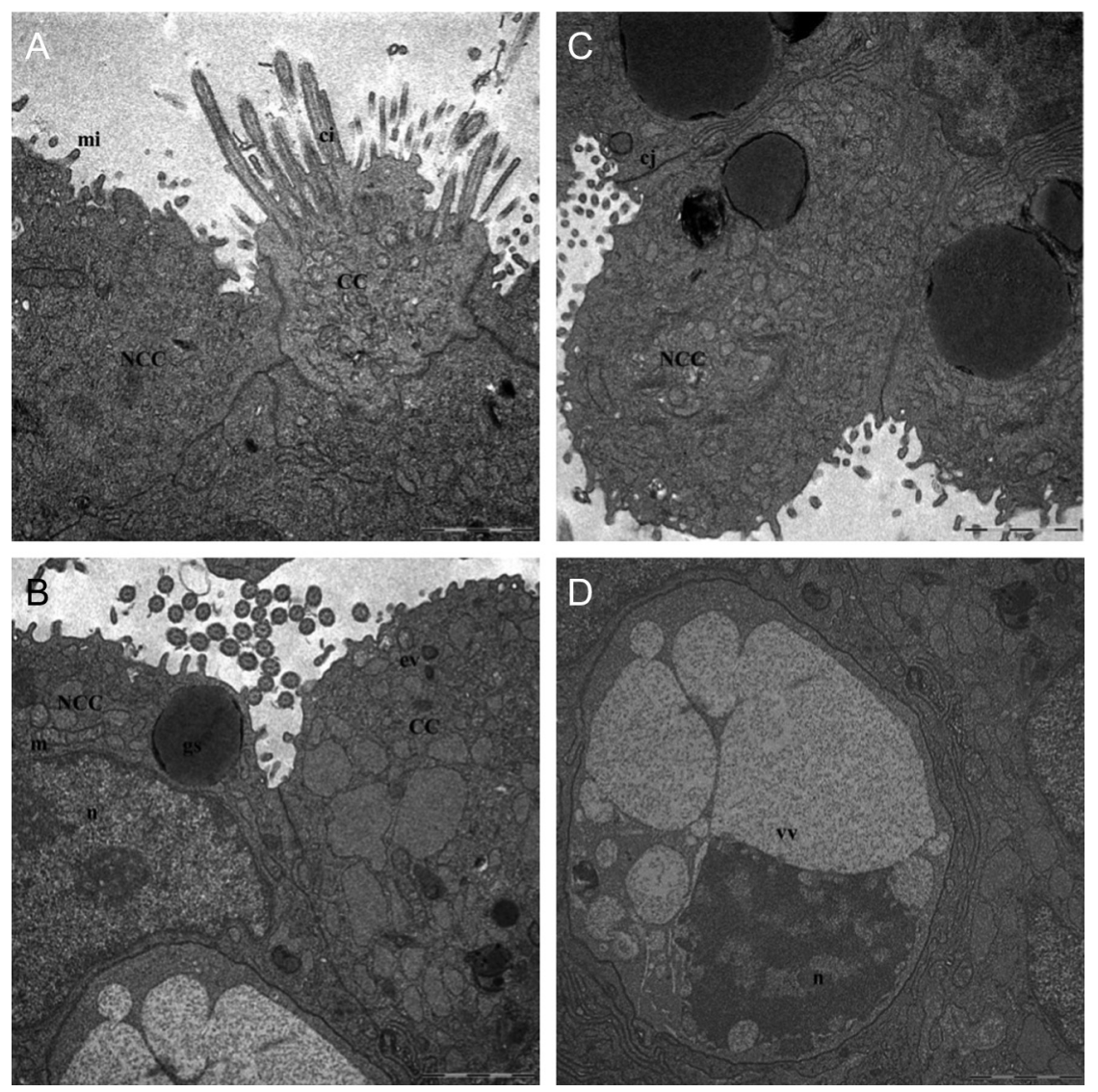

Figure 4 TEM observation. (A) Ciliated cells in longitudinal section. (B) Ciliated cells were characterized by a diffuse presence of rough endoplasmic reticulum throughout the cytoplasm and some endocytic vesicle in the apical region. (C) Non-ciliated cells often displayed microvilli on the apical protrusion and were characterized by an electron-dense cytoplasm containing a lobate nucleus rich in dispersed heterochromatin, dark granules of secretion in their supranuclear cytoplasm, elongated mitochondria and a rich endoplasmic reticulum. The presence of cell junctions in the apical portion of these cells indicates the polarization of these cells that are also closely connected to each other through interdigitations of membrane. (D) Cells with a large nucleus with disperse heterochromatin and voluminous vesicles containing electron-lucent secrete were detected under the epithelial cells (Fig. 3B and D). CC, ciliated cells; ci, cilia; cj, cell junction; ev, endocytic vesicle; gs, granule of secretion; m, mitochondria; mi, microvilli; $\mathrm{n}$, nucleus; NCC, non-ciliated cells; $\mathrm{vv}$, voluminous vesicle.
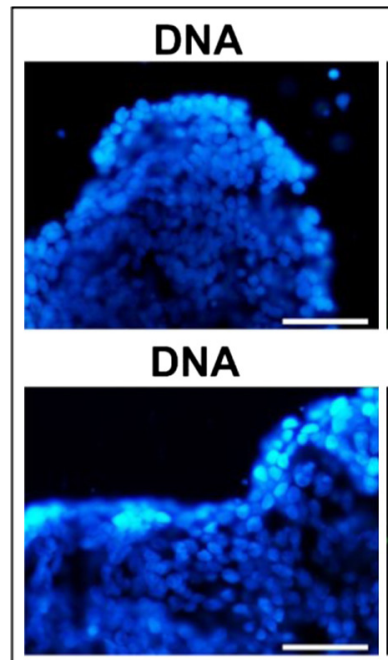

DNA

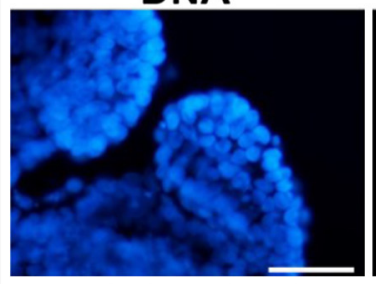

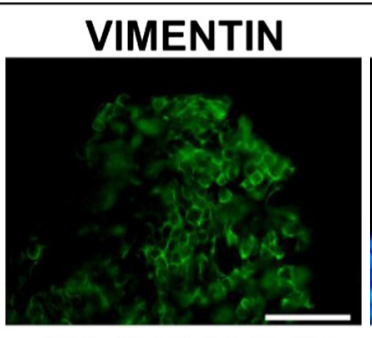

CYTOKERATIN

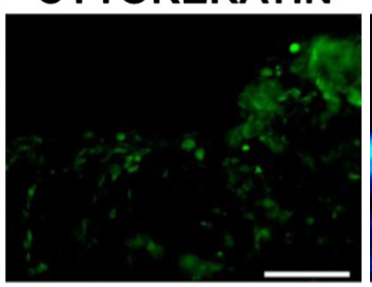

NEG CTRL

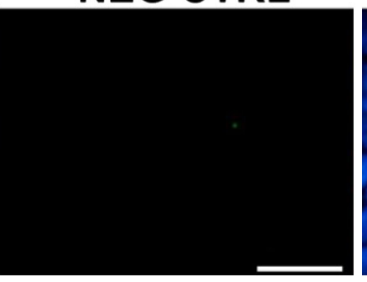

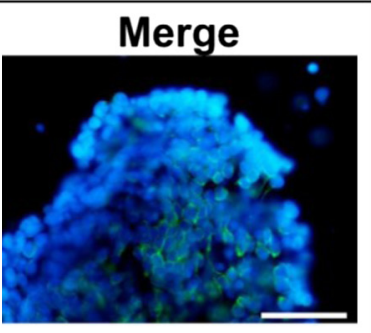

Merge

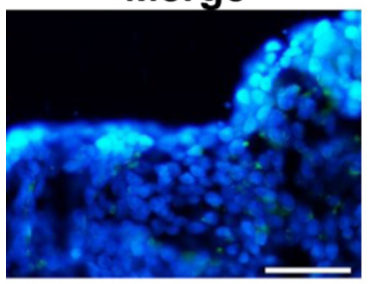

Merge

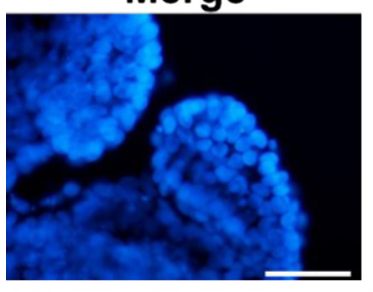

Figure 5 Immunocytochemistry. Multicellular spheroids exhibited positive immunostaining for cytokeratin and vimentin. Figures in the left column were obtained by staining with DAPI. Figures in center column show specific staining and control (CTRL). Figures in right column were merge images. Magnification $40 \times$. Scale bar $50 \mu \mathrm{m}$. 


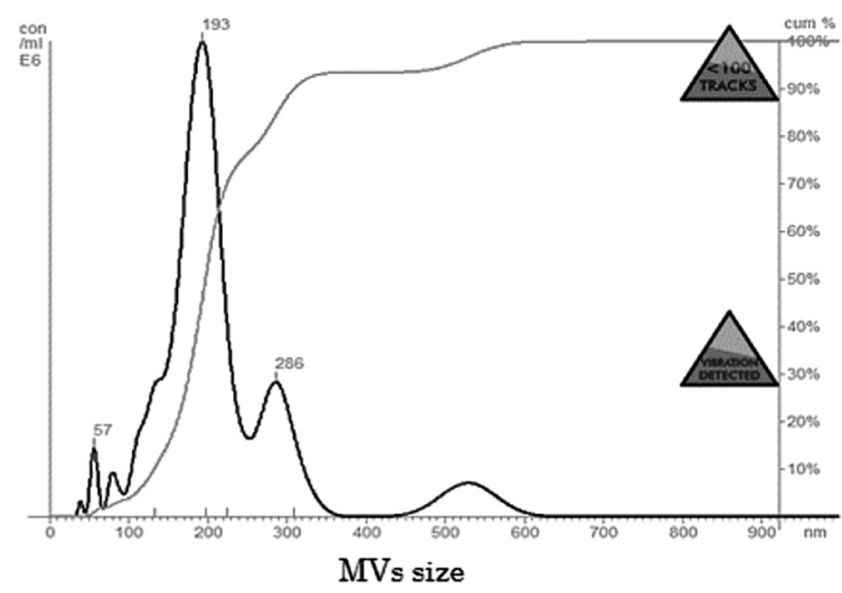

Figure 6 Measurement of MVs. NanoSight analysis relates MV size (in abscissa) to their concentration (in ordinate).

within the cytoplasm was visible $72 \mathrm{~h}$ after the start of IVM, as shown in the Fig. 10C and D.

\section{Discussion}

The study of the interactions of oviductal cells and their secretions with gametes and embryos at cellular and molecular level is fundamental in the comprehension of early reproductive mechanisms and in the development and refinement of reproductive biotechnologies (Gualtieri et al. 2012).

The objective of the present study was to understand the effect of secretome of epithelial oviductal cells on canine oocyte IVM. We focused our attention on epithelial cells of the isthmus-ampullar oviductal tract because in vivo this oviductal environment in the dog has some unique qualities that are beneficial for extending oocyte viability and supporting their maturation but at the moment is not given to know which factors are so important and where they are produced. In addition, for this purpose, IVM was performed taking into account all the most effective conditions reported in literature and previously described. In the biphasic system, COCs were cultured for $24 \mathrm{~h}$ with $\mathrm{LH}$ to simulate the $\mathrm{LH}$ peak, which occurs in the early estrus, and that leads to ovulation. In conjunction with the LH surge in vivo, a concomitant gradual increase in serum concentrations of progesterone becomes apparent, and for this reason, for other $48 \mathrm{~h}$, the oestrous bitch serum with progesterone level higher than $10 \mathrm{ng} / \mathrm{mL}$ was added. In addition to these experimental conditions, in this second step, COCs were cocultured with oviductal epithelial cells that were cultivated in two different ways: in monolayer or in tri-dimensional multicellular spheroids in suspension. The results showed that co-culture with epithelial cells in monolayer provided statistically $(P<0.05)$ less maturation rate (MII) compared to co-culture in the presence of multicellular spheroids ( $10.71 \%$ vs $20.00 \%)$. Both IVM conditions were statistically $(P<0.05)$ better than control in SOF medium alone, without helper cells $(8.66 \%)$. The difference between the two kinds of oviductal epithelial cells could be explained taking into account that, during culture, oviductal monolayers can de-differentiate losing cell polarity, cell height, ciliation, secretory activity and responsiveness to hormones, showing signs of alteration after $24-48 \mathrm{~h}$ post confluence (Rottmayer et al. 2006, Sostaric et al. 2008, Gualtieri et al. 2009, Ulbrich et al. 2010). For this reason, we tried to use the multicellular spheroids that spontaneously aggregate after the squeezing of canine oviduct. These multicellular spheroids are heterogeneous and mainly composed of epithelial, ciliated and non-ciliated cells. As demonstrated by TEM analysis, these cells maintain their polarity and their secretory activities evidenced by the occurrence of several secretory granules. The presence of several protrusions and short scattered microvilli suggests that they could mostly be derived from region of the ampulla (Desantis et al. 2011). In addition to these cells, multicellular spheroids are also composed of stromal cells, positive to vimentin.

Considering the better maturation rate, these multicellular spheroids seem to better mimic what normally occurs in vivo, probably thanks to the cellto-cell interactions between epithelial cells and between epithelial and mesenchymal cells inside these aggregates.

This suggests that the oviduct epithelium actively participates in the production of a unique biochemical milieu able to promote the in vivo oocyte maturation. Many growth factors, receptors and binding proteins are secreted into the culture medium by these so-called 'helpers' cells' (Van Langendonckt et al. 1996, Izquierdo et al. 1999) and the potential of these medium, called CM, is already known for a long time, mainly for in vitro embryo production. ljaz et al. (1994) and

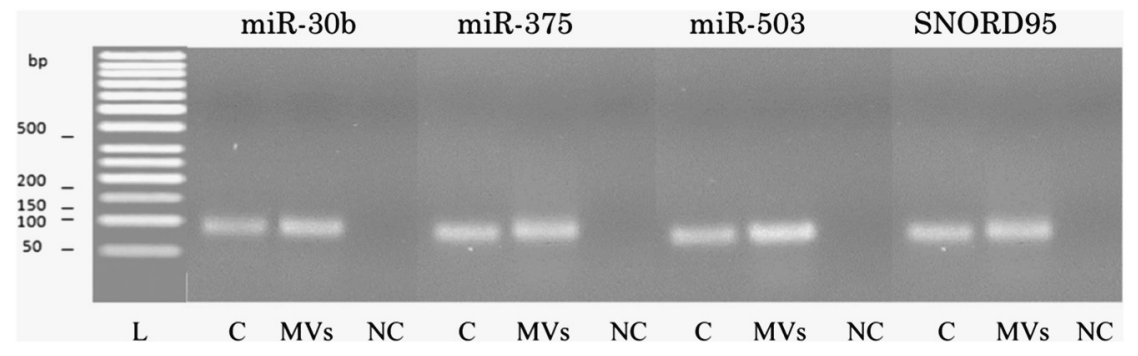

Figure 7 Identification of mi-RNAs. PCR analysis, identified three specific miRNAs (miR-30b, miR-375, miR-503), both in MVs and oviductal cells. $\mathrm{C}$ is cells, MVs is microvesicles and NC is negative control. SNORD95 was used as positive control. 


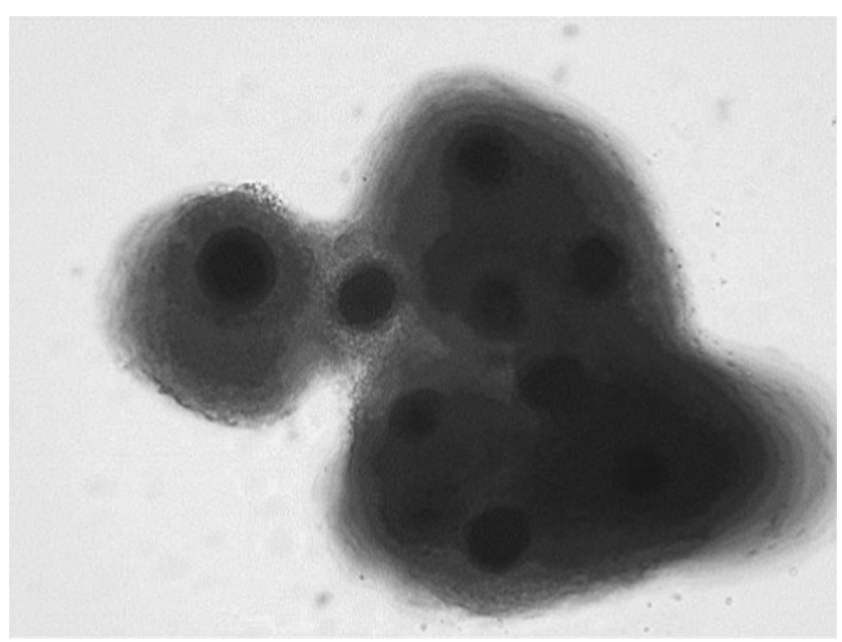

Figure 8 Morphology of matured oocytes. Cumulus expansion of oocytes cultured with $100 \times 10^{6} \mathrm{MVs} / \mathrm{mL}$.

Zhu et al. (1994) defined the CM as a complex matrix of secreted products from cells, in particular, growth factors, cytokines and glycoproteins that may influence the development of early preimplantation embryos. Some experiments have shown that the use of CM provides embryo developmental rates similar to those obtained in the co-culture systems (Kobayashi et al. 1992, Mermillod et al. 1993, Lee et al. 2003), with the benefit of not having animal cells in the embryo culture. Conditioned medium was also studied on porcine gamete to reduce polyspermy rates and improve embryo development (Bureau et al. 2000).

To date, the effect of different components of oviductal $\mathrm{CM}$ on canine IVM has not been investigated. Since in vivo canine oocytes interacts with the oviduct for a prolonged time and, in vitro, multicellular spheroids provided the better maturation rate, this study investigated the effect of different components of multicellular spheroid secretome on the canine oocyte MII rate.

$\mathrm{CM}$ is composed of soluble factors plus MVs. Consequently, CM in toto, MVs and $\mathrm{SN}$, collected after removal of $\mathrm{MVs}$, were investigated to recognize which of these components, if not all, have had effects on oocyte maturation, in terms of MII rate.

At first, the presence of MVs in CM produced by multicellular spheroids was identified. By their size, it was possible to classify these $\mathrm{MVs}$ as shedding vesicles, also known as ectosomes or microparticles, that originate from direct budding and 'blebbing' of the plasma membrane. These MVs are different from exosomes that arise from the cell membrane endosomal compartment and are released into the extracellular space after fusion of multivesicular bodies with the plasma membrane. Exosomes tend to be homogeneous in size $(30-120 \mathrm{~nm})$ while shedding vesicles are more heterogeneous (ranging from $100 \mathrm{~nm}$ to $1 \mu \mathrm{m}$ ). The multicellular spheroid-derived MVs had an average size of $234 \pm 23 \mathrm{~nm}$ and in each $\mathrm{ml}$ of $\mathrm{CM}, 54 \times 10^{6} \mathrm{MVs}$ Reproduction (2017) 154 167-180 were present. Obviously, these data refer to in vitro study and no information about their production during in vivo conditions is available.

The different components of secretome were added in the second step of the biphasic IVM system matching the co-culture with epithelial cells in monolayer or by multicellular spheroids. The results of our study suggested that the exposure of canine COCs to the various fractions of secretome provided dissimilar rates of MII. Indeed, CM and SN gave respectively 9.09\% and $7.14 \%$ of MII that were not statistically different $(P<0.05)$ from the rate provided by epithelial cells in monolayer $(10.71 \%)$. The first insight about these results indicated that, probably, $\mathrm{CM}$ and $\mathrm{SN}$ were used too much diluted ( $10 \%$ of SOF composition) to provide an adequate amount of soluble and non-soluble factors, but the maturation in whole $\mathrm{CM}$ or $\mathrm{SN}$, or in lower rate, did not provide MII attainment (data not shown). The $\mathrm{CM}$ is rich of soluble and non-soluble signal but
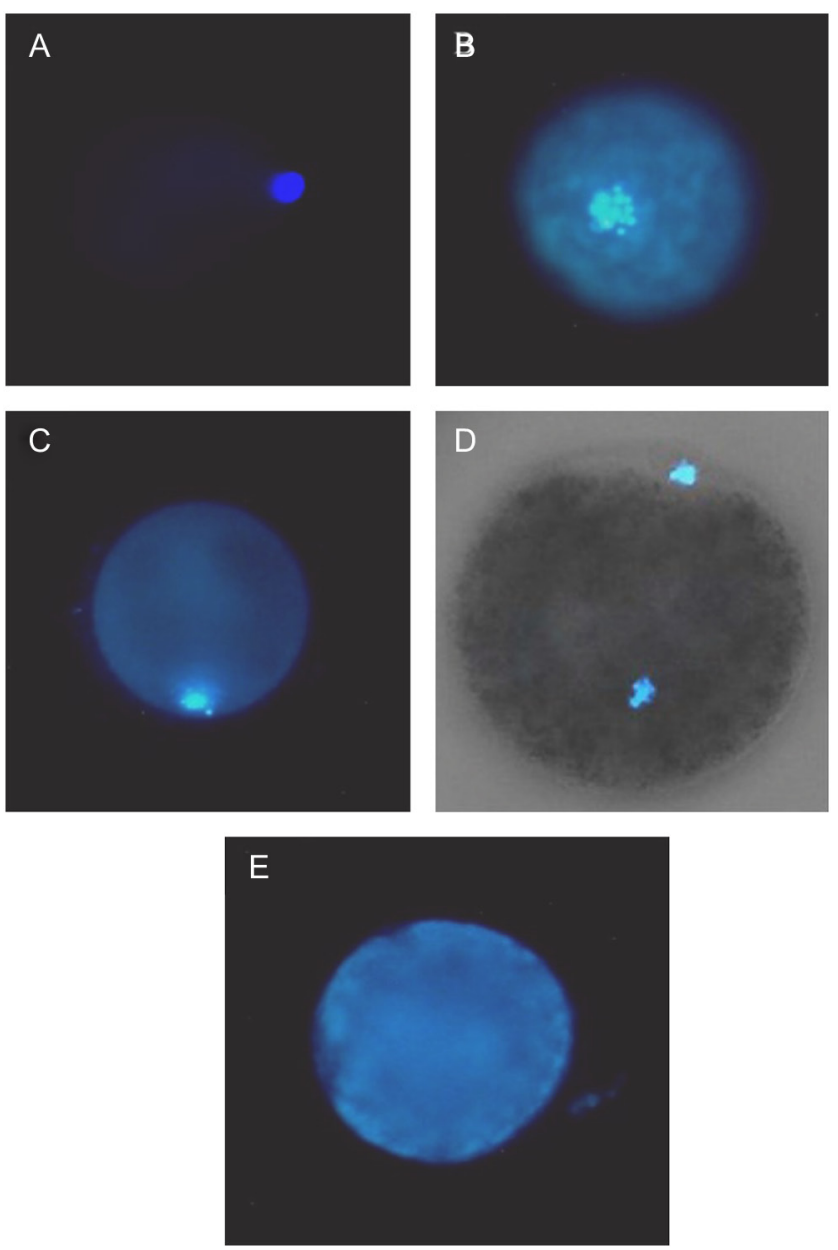

Figure 9 Nuclear stages of oocytes after $72 \mathrm{~h}$ of culture. Oocytes stained with Hoechst 33342 and evaluated under fluorescence microscopy, demonstrating (A) germinal vesicle $(G V),(B)$ germinal vesicle break down (GVBD), (C) metaphase I (MI), (D) metaphase II (MII), (E) degenerated (DEG) oocytes. Magnification 20×. 
Table 1 Effects of different experimental conditions on IVM of canine oocytes.

\begin{tabular}{|c|c|c|c|c|c|c|}
\hline \multirow[b]{2}{*}{ Media } & \multirow{2}{*}{$\begin{array}{c}\text { Assessed } \\
\text { oocytes } \\
\left(\mathrm{n}^{\circ}\right)\end{array}$} & \multicolumn{5}{|c|}{ Meiotic stages } \\
\hline & & GV (\%) & GVBD (\%) & MI (\%) & MII $(\%)$ & DEG $(\%)$ \\
\hline IVM control SOF + LH/SOF + serum & 82 & $17(20.73)^{\mathrm{a}}$ & $39(47.56)^{\mathrm{a}}$ & $5(6.1)$ & $3(8.66)^{\mathrm{a}}$ & $18(21.95)$ \\
\hline $\mathrm{SOF}+\mathrm{LH} / \mathrm{SOF}+$ serum + monolayer of epithelial cells & 84 & $18(21.43)^{\mathrm{a}}$ & $38(45.24)^{\mathrm{a}}$ & $6(7.14)$ & $9(10.71)^{\mathrm{a}}$ & $13(15.48)$ \\
\hline $\mathrm{SOF}+\mathrm{LH} / \mathrm{SOF}+$ serum + multicellular spheroids & 79 & $10(12.66)^{\mathrm{a}}$ & $23(29.11)^{b}$ & $10(12.66)$ & $16(20.00)^{b}$ & $20(25.32)$ \\
\hline $\mathrm{SOF}+\mathrm{LH} / \mathrm{SOF}+$ serum $+10 \% \mathrm{CM}$ & 88 & $15(17.05)^{\mathrm{a}}$ & $34(38.64)^{\mathrm{a}}$ & $9(10.23)$ & $8(9.09)^{\mathrm{a}}$ & $22(25.00)$ \\
\hline $\mathrm{SOF}+\mathrm{LH} / \mathrm{SOF}+$ serum $+10 \% \mathrm{SN}$ & 84 & $22(26.19)^{\mathrm{a}}$ & $37(44.05)^{\mathrm{a}}$ & $6(7.14)$ & $6(7.14)^{\mathrm{a}}$ & $13(15.48)$ \\
\hline $\mathrm{SOF}+\mathrm{LH} / \mathrm{SOF}+$ serum $+25 \times 10^{6} \mathrm{MVs}$ & 54 & $15(27.78)^{\mathrm{a}}$ & $14(25.93)^{b}$ & $10(18.52)$ & $3(5.56)^{\mathrm{a}}$ & $12(22.22)$ \\
\hline $\mathrm{SOF}+\mathrm{LH} / \mathrm{SOF}+$ serum $+50 \times 10^{6} \mathrm{MVs}$ & 58 & $9(15.52)^{\mathrm{a}}$ & $10(17.24)^{b}$ & $11(18.97)$ & $5(8.62)^{\mathrm{a}}$ & $23(39.65)$ \\
\hline $\mathrm{SOF}+\mathrm{LH} / \mathrm{SOF}+$ serum $+75 \times 10^{6} \mathrm{MVs}$ & 59 & $7(11.86)^{\mathrm{a}}$ & $17(28.81)^{b}$ & $7(11.86)$ & $12(20.34)^{b}$ & $16(27.12)$ \\
\hline $\mathrm{SOF}+\mathrm{LH} / \mathrm{SOF}+$ serum $+100 \times 10^{6} \mathrm{MVs}$ & 55 & $6(10.91)^{\mathrm{a}}$ & $16(29.10)^{b}$ & $9(16.36)$ & $12(21.82)^{b}$ & $12(21.82)$ \\
\hline $\mathrm{SOF}+\mathrm{LH} / \mathrm{SOF}+$ serum $+150 \times 10^{6} \mathrm{MVs}$ & 54 & $6(11.11)^{\mathrm{a}}$ & $12(22.22)^{\mathrm{b}}$ & $10(18.52)$ & $5(9.26)^{\mathrm{a}}$ & $21(38.89)$ \\
\hline
\end{tabular}

Different superscripts in columns indicate $P<0.05$.

can be considered a spent medium because, during cell metabolism, some molecules (for example the level of glucose) decrease (Pereira et al. 2014), and this could influence the oocyte metabolism negatively.

Microvesicles were tested at different amounts, and taking into account that one milliliter of $\mathrm{CM}$ contained $54 \times 10^{6}$ particles $/ \mathrm{mL}$, the experiment was performed using between 25 and $150 \times 10^{6} \mathrm{MVs}$ per $\mathrm{mL}$ of SOF. The better results were obtained at the concentration of 75 and $100 \times 10^{6} \mathrm{MVs} / \mathrm{mL}(20.34 \%$ and $21.82 \%$ of $\mathrm{MII}$ respectively) that were not statistically different $(P<0.05)$ from the rate provided by co-culture with multicellular spheroids (20\%). The higher concentration of $\mathrm{MVs}$ $\left(150 \times 10^{6} \mathrm{MVs} / \mathrm{mL}\right)$ gave statistically $(P<0.05)$ lower rate of MII (9.26) compared to the other two amounts.

To understand the good efficacy of MVs, we performed other two studies in order to investigate if oocytes were able to uptake these MVs and to check the presence, either in epithelial oviductal cells or in MVs, of some miRNAs, which emerge from the literature to be important for oocyte maturation. Certainly, cumulus cells are involved in paracrine mechanism as a bridge between oviduct and oocytes considering that they incorporated a significant amount of labeled MVs before the oocyte uptake. Moreover, recently, it was identified that the miRNA-378 present in the cumulus cells is involved in the maturation of porcine oocyte. Its overexpression alters the cumulus expansion and decreases the expression of genes associated either to the cumulus expansion or to the oocyte maturation (Pan et al. 2015). About the involvement of miRNA in oocyte maturation, Tesfaye et al. (2009) showed that between the immature and mature bovine oocyte, a difference of 59 miRNAs exists, of which, 31 are preferably expressed in the immature oocyte and 28 in the mature ones. Our study found that oviductal cells and their MVs contain miR-30b, miR-375 and miR503 that can be considered particularly interesting for the canine IVM oocytes because they are involved in follicular growth and oocyte maturation. Pathway analysis revealed that these miRNAs target factors such as WNT, MAPK, ERb $\beta, T G F \beta$, neurotrophin and ubiquitin (da Silveira et al. 2012, Sohel et al. 2013, Santonocito et al. 2014). Review of Machtinger et al. (2016) reports that WNT molecules are glycoproteins involved in follicular growth, luteogenesis and steroidogenesis. The members of the TGF $\beta$ superfamily, including inhibin, activin, bone morphogenetic protein 15 (BMP15) and growth differentiation factor 9 (GDF9), are expressed in the oocyte from very early stages and are responsible for follicular growth and oocyte maturation. The MAPK pathway stimulates granulosa
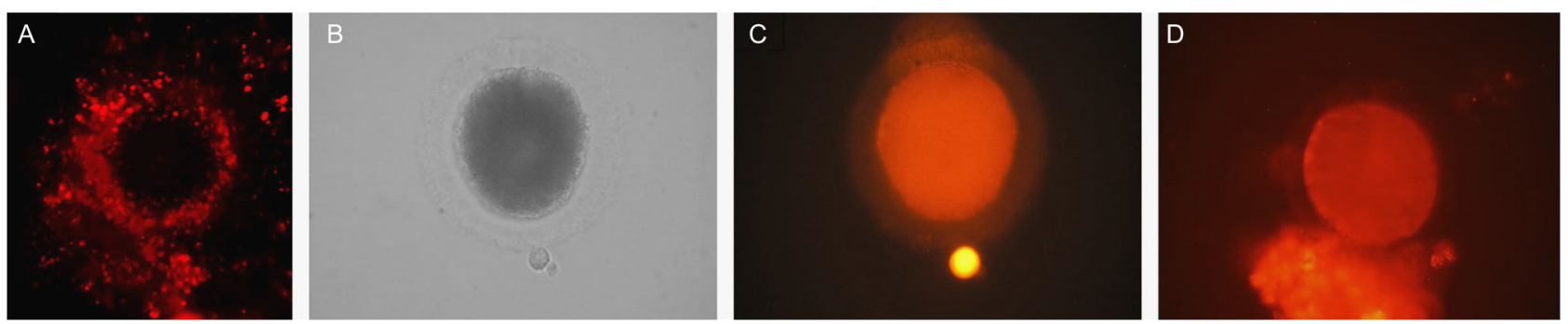

Figure 10 Incorporation of MVs by oocytes. (A) MVs, labeled with $\mathrm{PKH}-26$, are present within the cumulus cells, since $48 \mathrm{~h}$ of culture but not in oocyte cytoplasm. (B) Oocyte observed under transmitted visible light evidencing one cell of cumulus oophorus. (C) The same oocyte observed under fluorescent microscopy. The considerable incorporation of MVs within the cumulus cell and into the cytoplasm of oocyte at MI stage after 72 of IVM become clearly visible. (D) Oocyte with MVs incorporated in its cytoplasm and its partial cumulus oophorus. 
cell proliferation and cumulus expansion. Furthermore, together with the ERb $\beta$ pathway, the MAPK pathway promotes the resumption of meiosis in the oocyte. The ubiquitin-mediated pathway modulates oocyte meiotic maturation and early mitotic division in embryos, while the neurotrophin-signaling pathway regulates oogenesis and follicle formation. Considering that canine oocyte maturation occurs in the oviduct, it is conceivable that these miRNAs are present in the oviductal cells to be transferred to the oocytes for the purpose of their maturation. This is different compared to other species, for example in women, where these miRNAs were found in follicular fluid (place designed for oocyte maturation) and accumulate in granulosa cells and/or the cumulus cells (Sohel et al. 2013).

Through identification of these three miRNAs, perhaps it would be possible to explain why higher MVs doses lowered the MII rate to $9.26 \%$. Two studies reported high levels of miR-375 in exosomes from older vs younger mares. This miRNA targets TGF $\beta$, suppressing the TGF $\beta$ pathway leading to impaired oocyte maturation in older females (Knight \& Glister 2006, da Silveira et al. 2012). An excessive dose of MVs, and in our case of the miR375 would, therefore, have a deleterious, rather than beneficial, effect on oocyte maturation.

\section{Conclusions}

The results of this study show that even in the absence of cell-cell contact, the secretome produced by oviductal cells can exert beneficial actions on target cells, in this case represented by oocytes. Apparently, not the soluble components of the CM but the content of the microvesicles, with specific miRNAs, can contribute to the canine oocyte maturation.

Obviously, more studies will be needed to better understand the total cargo of miRNA contained in oviductal cells and their MVs and to understand if other miRNAs, involved in oocyte maturation, are preferably compartmentalized in these MVs. In this case, the addition of MVs or, preferably, the addition of specific miRNAs, or other biomolecules that may be involved in maintaining oocyte vitality, could potentially improve the rate of in vitro maturation, giving an improvement to the reproductive in vitro technologies in the canine species.

Moreover, this study provides a useful starting point for further studies related to the paracrine mechanisms of communication between oviduct and oocytes.

\section{Declaration of interest}

The authors declare that there is no conflict of interest that could be perceived as prejudicing the impartiality of the research reported.

\section{Funding}

This study was supported by grants from Università Degli Studi di Milano, Milano, Italy.

\section{Acknowledgements}

The authors wish to thank Dott.ssa Maria Chiara Deregibus and Prof Giovanni Camussi (Department of Internal Medicine and Molecular Biotechnology Center, University of Torino, Torino, Italy) for their skilled assistance in NanoSight instrument use, and Dott.ssa Nadia Santo e Laura Madaschi (Department of Biology, Università Degli Studi di Milano, Milano, Italy) for their skilled assistance in TEM. Authors wish to thank Vetoquinol for providing the Lutropin used in the IVM protocol.

\section{References}

Apparicio M, Mostachio GQ, Motheo TF, Alves AE, Padilha L, PiresButler EA, Savi PAP, Uscategui RAR, Luvoni GC \& Vicente RR 2014 Distribution of cortical granules and meiotic maturation of canine oocytes in bi-phasic systems. Reproduction Fertility and Development 27 1082-1087. (doi:10.1071/RD14022)

Ariu F, Fois S, Bebbere D, Ledda S, Rosati I, Zedda MT, Pau S \& Bogliolo L 2012 The effect of okadaic acid on meiotic maturation of canine oocytes of different size. Theriogenology 77 46-52. (doi:10.1016/j. theriogenology.2011.07.013)

Brugger N, Otzdorff C, Walter B, Hoffmann B \& Braun J 2011 Quantitative determination of progesterone (P4) in canine blood serum using an enzyme-linked fluorescence assay. Reproduction in Domestic Animals 46 870-873. (doi:10.1111/j.1439-0531.2011.01757.x)

Bureau M, Bailey JL \& Sirard MA 2000 Influence of oviductal cells and conditioned medium on porcine gametes. Zigote 8 139-144. (doi:10.1017/S0967199400000915)

Camussi G, Deregibus MC, Bruno S, Cantaluppi V \& Biancone L 2010 Exosomes/microvesicles as a mechanism of cell-to-cell communication. Kidney International 78 838-848. (doi:10.1038/ki.2010.278)

Chebrout M, De Lesegno CV, Reynaud K, Chat S \& Chastant-Maillard S 2009. Nuclear and cytoplasmic maturation of canine oocytes related to in vitro denudation. Reproduction Domestic Animal 44 243-246. (doi:10.1111/j.1439-0531.2009.01371.x)

D'Amico F 2005 A polychromatic staining method for epoxy embedded tissue: a new combination of methylene blue and basic fuchsine for light microscopy. Biotechnic and Histochemistry 80 207-210. (doi:10.1080/10520290600560897)

da Silveira JC, Veeramachaneni DN, Winger QA, Carnevale EM \& Bouma G) 2012 Cell-secreted vesicles in equine ovarian follicular fluid contain miRNAs and proteins: a possible new form of cell communication within the ovarian follicle. Biology of Reproduction 86 71. (doi:10.1095/ biolreprod.111.093252)

Desantis S, Zizza S, Accogli G, Acone F, Rossi R \& Resta L 2011 Morphometric and ultrastructural features of the mare oviduct epithelium during oestrus. Theriogenology 75 671-678.

Evecen M, Cirit U, Demir K, Hamzaoglu AI, Bakırer I, Pabuccuoglu S \& Birler S 2011 Adding hormones sequentially could be an effective approach for IVM of dog oocytes. Theriogenology 75 1647-1651. (doi:10.1016/j.theriogenology.2011.01.004)

Eyestone WH \& First NL 1989 Co-culture of early cattle embryos to the blastocyst stage with oviducal tissue or in conditioned medium. Journal Reproduction and Fertility 85 715-720. (doi:10.1530/jrf.0.0850715)

Gilchrist RB, Lane M \& Thompson JG 2008 Oocyte-secreted factors: regulators of cumulus cell function and oocyte quality. Human Reproduction Update 14 159-177. (doi:10.1093/humupd/dmm040)

Gualtieri R, Mollo V, Duma G \& Talevi R 2009 Redox control of surface protein sulphhydryls in bovine spermatozoa reversibly modulates sperm adhesion to the oviductal epithelium and capacitation. Reproduction 138 33-43. (doi:10.1530/REP-08-0514) 
Gualtieri R, Mollo V, Braun S, Barbato V, Fiorentino I \& Talevi R 2012 Long-term viability and differentiation of bovine oviductal monolayers: bidimensional versus three-dimensional culture. Theriogenology $\mathbf{7 8}$ 1456-1464. (doi:10.1016/j.theriogenology.2012.06.010)

Guraya SS 1965 A histochemical analysis of lipid yolk deposition in the oocytes of cat and dog. Journal Experimental Zoology 160 123-136. (doi:10.1002/jez.1401600111)

Hatoya S, Sugiyama Y, Torii R, Wijewardana V, Kumagai D, Sugiura K, Kida K, Kawate N, Tamada H, Sawada T et al. 2006 Effect of co-culturing with embryonic fibroblasts on IVM, IVF and IVC of canine oocytes. Theriogenology 66 1083-1090. (doi:10.1016/j. theriogenology.2005.12.015)

Hewitt DA \& England GCW 1998 The effect of oocytes maturation and age upon oocyte nuclear maturation in vitro. Theriogenology 49 957-966. (doi:10.1016/S0093-691X(98)00044-2)

Holst PA \& Phemister RD 1971 The prenatal development of the dog: preimplantation events. Biology of Reproduction 5 194-206. (doi:10.1093/biolreprod/5.2.194)

Ijaz A, Lambert RD \& Sirard MA 1994 In vitro cultured bovine granulosa and oviductal cells secrete sperm motility maintaining factor(s). Molecular Reproduction and Development 37 54-60. (doi:10.1002/ mrd.1080370108)

Izquierdo D, Villamediana P \& Paramio MT 1999 Effect of culture media on embryo development from prepubertal goat IVM-IVF oocytes. Theriogenology 52 847-861. (doi:10.1016/S0093-691X(99)00177-6)

Kim MK, Fibrianto YH, Oh HJ, Jang G, Kim HJ, Lee KS, Kang SK, Lee BC \& Hwang WS 2004 Effect of betamercaptoethanol or epidermal growth factor supplementation on in vitro maturation of canine oocytes collected from dogs with different stages of the estrus cycle. Journal Veterinary Science 5 253-258.

Knight PG \& Glister C 2006 TGF-beta superfamily members and ovarian follicle development. Reproduction 132 191-206. (doi:10.1530/ rep.1.01074)

Kobayashi K, Takagi Y, Satoh T, Hoshi H \& Oikawa T 1992 Development of early bovine embryos to the blastocyst stage in serum-free conditioned medium from bovine granulosa cells. In Vitro Cellular and Developmental Biology 28 255-259. (doi:10.1007/BF02634241)

Lee YL, Lee KF, Xu JS, Kwok KL, Luk JM, Lee WM \& Yeung WSB 2003 Embryotrophic factor-3 from human oviductal cells affects the messenger RNA expression of mouse blastocyst. Biology of Reproduction 68 375-382.

Lopera-Vásquez R, Hamdi M, Fernandez-Fuertes B, Maillo V, BeltránBreña P, Calle A, Redruello A, López-Martín S, Gutierrez-Adán A, YañezMó $\mathbf{M}$ et al. 2016 Extracellular vesicles from BOEC in in vitro embryo development and quality. PLOS ONE 11 e0148083. (doi:10.1371/ journal.pone.0148083)

Luvoni GC, Chigioni S, Allievi E \& Macis D 2003 Meiosis resumption of canine oocytes cultured in the isolated oviduct. Reproduction Domestic Animal 38 410-414. (doi:10.1046/j.1439-0531.2003.00457.x)

Luvoni GC, Chigioni S, Allievi E \& Macis D 2005 Factors involved in vivo and in vitro maturation of canine oocytes. Theriogenology 63 41-59. (doi:10.1016/j.theriogenology.2004.03.004)

Machtinger R, Laurent LC \& Baccarelli AA 2016. Extracellular vesicles: roles in gamete maturation, fertilization and embryo implantation. Human Reproduction Update 22 182-193. (doi:10.1093/humupd/ dmv055)

Mermillod P, Vansteenbrugge A, Wils C, Mourmeaux JL, Massip A \& Dessy F 1993 Characterization of the embryotrophic activity of exogenous protein-free oviduct-conditioned medium used in culture of cattle embryos. Biology of Reproduction 49 582-587. (doi:10.1095/ biolreprod49.3.582)

Nickson DA, Boyd JS, Eckersall PD, Ferguson JM, Harvey MJA \& Renton JP 1993 Molecular biological methods for monitoring oocyte maturation and in vitro fertilization in bitches. Journal Reproduction Fertility Supplement 47 231-240. (doi:10.1051/rnd:2004065)

Otoi T, Murakami M, Fujii M, Tanaka M, Ooka A, Une S \& Suzuki T 2000a Development of canine oocytes matured and fertilised in vitro. Veterinary Record 146 52-53. (doi:10.1136/vr.146.2.52)

Otoi T, Fujii M, Tanaka M, Ooka A \& Suzuki T 2000b Canine oocyte diameter in relation to meiotic competence and sperm penetration. Theriogenology 54 535-542. (doi:10.1016/S0093-691X(00)00368-X)
Otoi T, Ooka A, Murakami M, Kurniani Karja NW \& Suzuki T 2001 Size distribution and meiotic competence of oocytes obtained from bitch ovaries at various stages of the oestrous cycle. Reproduction Fertility and Development 13 151-155. (doi:10.1071/RD00098)

Pan B, Toms D, Shen W \& Li J 2015 MicroRNA-378 regulates oocyte maturation via the suppression of aromatase in porcine cumulus cells. American Journal of Physiology: Endocrinology and Metabolism 308 E525-E534. (doi:10.1152/ajpendo.00480.2014)

Pereira T, Ivanova G, Caseiro AR, Barbosa P, Bàrtolo PJ, Santos JD, Luìs AL \& Maurıcio AC 2014 MSCs conditioned media and umbilical cord blood plasma metabolomics and composition. PLOS ONE 9 e113769 (doi:10.1371/journal.pone.0113769)

Raposo G \& Stoorvogel W 2013 Extracellular vesicles: exosomes, microvesicles, and friends. Journal of Cell Biology 200 373-383. (doi:10.1083/jcb.201211138)

Ratajczak J, Wysoczynski M, Hayek F, Janowska-Wieczorek A \& Ratajczak MZ 2006 Membrane-derived microvesicles: important and underappreciated mediators of cell-to-cell communication. Leukemia 20 1487-1495. (doi:10.1038/sj.leu.2404296)

Rieger D, Grisart B, Semple E, Van Langendonckt A, Betteridge KJ \& Dessy F 1995 Comparison of the effects of oviductal cell co-culture and oviductal cell-conditioned medium on the development and metabolic activity of cattle embryos. Journal of Reproduction and Infertility $\mathbf{1 0 5}$ 91-98. (doi:10.1530/jrf.0.1050091)

Rottmayer R, Ulbrich S, Kölle S, Prelle K, Neumüller C, Sinowatz F, Meyer H, Wolf E \& Hiendleder S 2006 A bovine oviduct epithelial cell suspension culture system suitable for studying embryo-maternal interactions: morphological and functional characterization. Reproduction 132 637-648. (doi:10.1530/rep.1.01136)

Saikhun J, Sriussadaporn S, Thongtip N, Pinyopummin A \& Kitiyanant Y 2008 Nuclear maturation and development of IVM/IVF canine embryos in synthetic oviductal fluid or in co-culture with buffalo rat liver cells. Theriogenology 69 1104-1110. (doi:10.1016/j. theriogenology.2008.01.024)

Santonocito $M$, Vento $M$, Guglielmino $M R$, Battaglia $R$, Wahlgren J, Ragusa M, Barbagallo D, Borzi P, Rizzari S, Maugeri M et al. 2014. Molecular characterization of exosomes and their microRNA cargo in human follicular fluid: bioinformatic analysis reveals that exosomal microRNAs control pathways involved in follicular maturation. Fertility and Sterility 102 1751-1761. (doi:10.1016/j. fertnstert.2014.08.005)

Silva AE, Rodriguez P, Cavalcante LF, Rodrigues BA \& Rodrigues JL 2009 The influence of oxygen tension on cumulus cell viability of canine COCs matured in high-glucose medium. Reproduction Domestic Animal 44 259-262. (doi:10.1111/j.1439-0531.2009.01406.x)

Skog J, Würdinger T, van Rijn S, Meijer DH, Gainche L, Sena-Esteves M, Curry WT Jr, Carter BS, Krichevsky AM \& Breakefield XO 2008 Glioblastoma microvesicles transport RNA and proteins that promote tumour growth and provide diagnostic biomarkers. Nature Cell Biology 10 1470-1476. (doi:10.1038/ncb1800)

Sohel MM, Hoelker M, Noferesti SS, Salilew-Wondim D, Tholen E, Looft C, Rings F, Uddin MJ, Spencer TE, Schellander K et al. 2013 Exosomal and non-exosomal transport of extra-cellular microRNAs in follicular fluid: implications for bovine oocyte developmental competence. PLOS ONE 8 e78505. (doi:10.1371/journal.pone.0078505)

Songsasen N \& Wildt DE 2005 Size of the donor follicle, but not stage of reproductive cycle or seasonality, influences meiotic competency of selected domestic dog oocytes. Molecular Reproduction and Development 72 113-119. (doi:10.1002/mrd.20330)

Songsasen N, Yu I \& Leibo SP 2002 Nuclear maturation of canineoocytes cultured in protein-free media. Molecular Reproduction and Development 62 407-415. (doi:10.1002/mrd.10130)

Sostaric E, Dieleman SJ, van de Lest CH, Colenbrander B, Vos PL, GarciaGil N \& Gadella BM 2008 Sperm binding properties and secretory activity of the bovine oviduct immediately before and after ovulation. Molecular Reproduction and Development 75 60-74. (doi:10.1002/ mrd.20766)

Tesfaye D, Worku D, Rings F, Phatsara C, Tholen E, Schellander K \& Hoelker M 2009 Identification and expression profiling of microRNAs during bovine oocyte maturation using heterologous approach. Molecular Reproduction and Development 76 665-677. (doi:10.1002/mrd.21005) 
Tesoriero JV 1982 A morphologic, cytochemical, and chromatographic analysis of lipid yolk formation in the oocytes of the dog. Gamete Research 6 267-279. (doi:10.1002/mrd.1120060309)

Thery C, Ostrowski M \& Segura E 2009 Membrane vesicles as conveyors of immune responses. Nature Reviews Immunology 9 581-593. (doi:10.1038/nri2567)

UlbrichSE,Zitta K, HiendlederS \&WolfE2010 In vitro systems for intercepting early embryo-maternal cross-talk in the bovine oviduct. Theriogenology 73 802-816. (doi:10.1016/j.theriogenology.2009.09.036)

Van Langendonckt A, Vansteenbrugge A, Donnay I, Van Soom A, Berg U, Semple E, Grisart B, Mermillod P, Brem G, Massip A et al. 1996 Three year results of in vitro production of bovine embryos in serumpoor bovine oviduct conditioned medium. An overview. Reproduction Nutrition Development 36 493-502. (doi:10.1051/rnd:19960505)

Viaris de Lesegno C, Reynaud K, Thoumire S \& Chastant-Maillard S 2008 Transcriptional reactivation during in vivo maturation of canine oocyte. In Proceedings of the 6th EVSSAR Congress and 6th International Symposium on Canine and Feline Reproduction, 9-11 July, Vienna, pp. 283-285.

Xu KP, Yadav BR, Rorie RW, Plante L, Betteridge KJ \& King WA 1992 Development and viability of bovine embryos derived from oocytes matured and fertilised in vitro and cocultured with bovine oviducal epithelial cells. Journal Reproduction and Fertility 94 33-43. (doi:10.1530/jrf.0.0940033)

Yamada S, Shimazu Y, Kawano Y, Nakazawa M, Naito K \& Toyoda Y 1993 In vitro maturation and fertilization of preovulatory dog oocytes. Reproduction and Fertility 47 227-229.

Zhang M, Ouyang H \& Xia G 2009 The signal pathway of gonadotrophinsinduced mammalian oocyte meiotic resumption. Molecular Human Reproduction 15 399-409. (doi:10.1093/molehr/gap031)

Zhu J, Barrat CL, Lippes J, Pacey AA \& Cooke ID 1994 The sequential effects of human cervical mucus, oviductal fluid, and follicular fluid on sperm function. Fertility and Sterility 61 1129-1135. (doi:10.1016/ S0015-0282(16)56768-5)

Received 24 February 2017

First decision 10 April 2017

Revised manuscript received 27 April 2017

Accepted 30 May 2017 